\title{
The Role of the Neurokinin-I Receptor in Stress-Induced Reinstatement of Alcohol and Cocaine Seeking
}

\author{
Jesse R Schank ${ }^{*,}$, Courtney E King', Hui Sun', Kejun Cheng', Kenner C Rice', Markus Heilig', \\ David Weinshenker ${ }^{3}$ and Jason $\mathbf{P}$ Schroeder ${ }^{3}$ \\ 'Laboratory of Clinical and Translational Studies, National Institute on Alcohol Abuse and Alcoholism, National Institutes of Health, Bethesda, \\ MD, USA; ${ }^{2}$ Chemical Biology Branch, National Institute on Alcohol Abuse and Alcoholism and National Institute on Drug Abuse, National \\ Institutes of Health, Bethesda, MD, USA; ${ }^{3}$ Department of Human Genetics, Emory University, Atlanta, GA, USA
}

\begin{abstract}
Neurokinin-I receptors (NKIRs) have been shown to mediate alcohol and opiate, but not cocaine reward in rodents. We recently reported that NKIR antagonism also blocks stress-induced reinstatement of alcohol seeking in rats, but it is presently unknown whether these antirelapse properties extend to other drug classes. Although some work has suggested that intracranial substance P (SP) infusion reinstates cocaine seeking following extinction, no studies have indicated a direct role for the NKIR in reinstatement of cocaine seeking. Here, we explored the effect of the NKIR antagonist L822429 on yohimbine-induced reinstatement of alcohol or cocaine seeking in Long-Evans rats. Consistent with our previous findings with footshock-induced reinstatement of alcohol seeking in Wistar rats, we found that L822429 attenuates yohimbine-induced reinstatement of alcohol seeking, but does not affect baseline alcohol self-administration. We observed a similar suppression of yohimbine-induced reinstatement of cocaine seeking by L822429, and found that Long-Evans rats exhibit greater sensitivity to NKIR antagonism than Wistar rats. Accordingly, Long-Evans rats exhibit differences in the expression of NKIRs in some subcortical brain regions. Combined, our findings suggest that while NKIR antagonism differentially influences alcoholand cocaine-related behavior, this receptor mediates stress-induced seeking of both drugs.

Neuropsychopharmacology (2014) 39, 1093-1 I01; doi:I0.1038/npp.2013.309; published online 27 November 2013
\end{abstract}

Keywords: substance P; self-administration; stress; ethanol; yohimbine; relapse

\section{INTRODUCTION}

Substance $\mathrm{P}(\mathrm{SP})$ is an 11-amino-acid member of the tachykinin family that preferentially binds to the neurokinin-1 receptor (NK1R). SP and the NK1R are found in regions that regulate anxiety, stress, and drug reward (Commons, 2010). SP release is induced by stressors, and central SP infusion has anxiogenic effects (Ebner et al, 2004, 2008a). Conversely, NK1R antagonists are anxiolytic and can reverse the behavioral effects of acute stress (Ebner and Singewald, 2006; Ebner et al, 2008b; Singewald et al, 2008).

The SP/NK1R system mediates reinforcement by opiates (Ripley et al, 2002; Barbier et al, 2012) and alcohol (Schank et al, 2012, 2013). NK1R - / - mice self-administer less morphine than wild-type animals, and do not show conditioned place preference (CPP) for this drug (Murtra et al, 2000; Ripley et al, 2002). Accordingly, NK1R antagonism suppresses heroin self-administration in rats (Barbier et al, 2012). Although more selectively targeting

*Correspondence: Dr JR Schank, National Institute on Alcohol Abuse and Alcoholism, Laboratory of Clinical and Translational Studies, National Institutes of Health, 10 Center Drive, Building 10-CRC, Room I-5330, Bethesda, MD 20892- I I08, USA, Tel: + | 30 | 4025305 , Fax: + I 30I 402 0445, E-mail: Jesse.Schank@nih.gov

Received 5 June 2013; revised 20 September 2013; accepted 3 October 2013; accepted article preview online 31 October 2013 escalated intake levels, the NK1R also appears to have a role in regulating alcohol consumption. NK1R antagonists suppress alcohol consumption in a high alcohol preferring strain of mice (C57/BL6J) and attenuate escalated alcohol self-administration in alcohol preferring $(\mathrm{P})$ rats, but do not affect alcohol self-administration in non-dependent Wistar rats (Thorsell et al, 2010; Schank et al, 2011, 2013). NK1R - / - mice on a C57/BL6J background also consume less alcohol than wild-type controls, and do not show alcohol CPP (George et al, 2008; Thorsell et al, 2010). The role of NK1R in drug reward appears to be selective for opioids and alcohol, and no evidence for its involvement in cocaine reward or reinforcement has been found (Murtra et al, 2000; Ripley et al, 2002; Gadd et al, 2003; Placenza et al, 2006).

Relapse is a key element of addictive disorders, and is in part driven by neurocircuitry distinct from that which mediates acute drug reward. Experiments using reinstatement of drug seeking following extinction, an animal model of relapse-like behavior (Le and Shaham, 2002; Shaham et al, 2003; Epstein et al, 2006), suggest that NK1R antagonism selectively attenuates stress-induced relapse to alcohol seeking, whereas cue-induced relapse is unaffected (Schank et al, 2011). The role of the NK1R in stress-induced reinstatement of opiate or psychostimulant seeking has not been explored. 
It has been suggested that the NK1R regulates cocaineinduced locomotion and dopamine release in the dorsal striatum (Kraft et al, 2001a, b; Noailles and Angulo, 2002; Loonam et al, 2003). Despite a lack of evidence supporting a direct role for the NK1R in cocaine reinforcement, one study showed that intracranial SP infusion can reinstate cocaine seeking following extinction (Placenza et al, 2005). However, in these experiments, NK1R antagonism was unable to block drug-primed reinstatement of cocaine seeking. Stress-induced reinstatement of cocaine seeking was not explored in these studies.

Given the general role of the SP/NK1R system in stress responses, and specifically in stress-induced reinstatement of alcohol seeking, we assessed the effect of the NK1R antagonist L822429 on yohimbine-induced reinstatement of cocaine seeking and self-administration of cocaine in LongEvans rats. Yohimbine is a pharmacological stressor that is anxiogenic in humans and, like footshock stress, can serve as a reinstatement stimulus for multiple classes of drugs in preclinical models (Lee et al, 2004; Shepard et al, 2004b; Le et al, 2005; Fletcher et al, 2008). We also assessed the effects of L822429 on natural reward by determining its effect on responding for a non-drug reinforcer, saccharin. To further compare the role of the NK1R in cocaine seeking to its role in alcohol-related behaviors, we tested the effect of L822429 on alcohol self-administration and yohimbine-induced reinstatement in Long-Evans rats. Because we found differential sensitivity to L822429 between Wistar rats in previous studies and the Long-Evans rats used here, we examined if there were any underlying differences in the state of the NK1R system by measuring the expression of NK1Rs in a selection of subcortical brain regions associated with self-administration or relapse-like behavior.

\section{MATERIALS AND METHODS}

\section{Animals}

Male Long-Evans or Wistar rats (175-225 g; Charles River, Wilmington, MA) were allowed at least 1 week habituation, after which they were handled daily for another week before experiments. Rats were housed on reversed light cycle (on 20:30, off 08:30 hours), and testing took place during the dark phase. Food and water were available ad libitum, except when stated. All procedures were in accordance with the National Institutes of Health Guide for the Care and Use of Laboratory Animals, and were approved by the Institutional Animal Care and Use Committees at Emory University and the National Institute on Alcohol Abuse and Alcoholism.

\section{Cocaine Self-Administration and Reinstatement}

To examine the effects of NK1R antagonism on operant cocaine self-administration, Long-Evans rats $(n=6)$ were trained on operant cocaine self-administration as described previously (Schroeder et al, 2013). Subjects were trained in 3-h sessions on an FR1 schedule following a single 2-h habituation session. Each subsequent operant cocaine selfadministration session began with extension of the inactive lever for $5 \mathrm{~min}$. Then, the house light was illuminated and the active lever extended. Responses on the active lever resulted in cocaine infusion $(0.5 \mathrm{mg} / \mathrm{kg}$ per infusion $)$ accompanied by illumination of a discrete light cue above the lever. Following a 20-s timeout period, the stimulus light was extinguished, and responses were again reinforced. Responses on the inactive lever had no programmed consequences. To prevent overdose, the session was terminated upon the attainment of 60 cocaine infusions. Following the establishment of stable responding $(<30 \%$ variability over 3 days), subjects were administered vehicle or $\mathrm{L} 822429$ (15 or $30 \mathrm{mg} / \mathrm{kg}$ ) $1 \mathrm{~h}$ before the next selfadministration session. Each rat received all treatments using a counterbalanced, within-subjects design, with 2 days to re-establish FR1 self-administration without antagonist injections between testing. Treatment conditions were compared using repeated-measures one-way ANOVA with the within-subjects factor of L822429 dose. Post hoc group comparisons were performed using Newman-Keuls tests.

To examine the effects of NK1R antagonism on yohimbine-induced reinstatement of cocaine-seeking, a separate cohort of Long-Evans rats $(n=8)$ was trained on operant cocaine self-administration for 10 days as described above. Following establishment of stable responding, subjects were left undisturbed in their home cages for 7 days, after which they were given 3-4 massed $1 \mathrm{~h}$ extinction trials (separated by 30-90 min) daily. Other than the length of session (1 vs $3 \mathrm{~h})$, the only difference between maintenance and extinction sessions was that no syringe was connected to the infusion pump during extinction, such that active lever responses resulted in the illumination of the stimulus light and activation of the infusion pump without cocaine delivery. Subjects were extinguished until active lever presses over three consecutive extinction sessions were $<25 \%$ of the average active lever presses during the last 3 days of maintenance. Once extinction criteria were met, rats received pretreatment with vehicle or L82229 $(15 \mathrm{mg} / \mathrm{kg})$ $30 \mathrm{~min}$ before a dose of yohimbine $(2.5 \mathrm{mg} / \mathrm{kg})$ that reliably reinstates cocaine-seeking behavior (Shepard et al, 2004a; Feltenstein and See, 2006; Schroeder et al, 2013). Thirty minutes following yohimbine injection, rats were tested for reinstatement in a single $3 \mathrm{~h}$ session under extinction conditions. After this test, rats were re-extinguished and then given a second yohimbine-induced reinstatement test with the opposite pretreatment. Pretreatments were given in a counterbalanced order for a within-subjects design. Treatment conditions were compared using repeatedmeasures one-way ANOVA, and post hoc group comparisons were performed using Newman-Keuls tests.

\section{Saccharin Self-Administration}

Rats $(n=7)$ were trained to lever press for $0.1 \mathrm{ml}$ saccharin in 30 min sessions on an FR1 schedule, with $22 \mathrm{~h}$ of water deprivation before the first 3 sessions but not thereafter. Saccharin concentrations (w/v) were $0.2 \%$ for 4 days, $0.1 \%$ for 3 days and then $0.05 \%$. Once the $0.05 \%$ concentration was reached, a $5 \mathrm{~s}$ timeout was initiated following saccharin delivery, during which a cue light was illuminated over the active lever. After 5 days of FR1 responding, the response requirement was increased to FR3 for 13 days, after which stable responding was established. Rats were then injected with vehicle or L822429 (15 or $30 \mathrm{mg} / \mathrm{kg}$ ) $1 \mathrm{~h}$ before the next 
self-administration session. Each rat received all treatments in a counterbalanced, within-subjects design, with 2 days to re-establish FR3 self-administration without drug injections between testing. Treatment conditions were compared using repeated-measures one-way ANOVA with the within-subjects factor of L822429 dose. Post hoc group comparisons were performed using Newman-Keuls tests.

\section{Locomotor Activity}

Rats ( $n=6$ per group) were injected, in a between-subjects design, with vehicle or L822429 $(15 \mathrm{mg} / \mathrm{kg}), 1 \mathrm{~h}$ before the start of the locomotor activity session, which lasted for $1 \mathrm{~h}$. Treatment groups were compared using independent samples $t$-tests.

\section{Alcohol Self-Administration and Reinstatement}

Self-administration training and testing were carried out as described previously (Cippitelli et al, 2010; Schank et al, 2011). Briefly, animals were trained to acquire stable rates of lever pressing for $10 \%(\mathrm{v} / \mathrm{v}$, in water) alcohol using a saccharin-fading procedure. Alcohol solution was delivered on a FR1 schedule into a drinking receptacle in a $0.1 \mathrm{ml}$ volume during $30 \mathrm{~min}$ sessions. Each alcohol delivery was followed by a $5 \mathrm{~s}$ timeout interval during which responses were recorded but not reinforced. A cue light was illuminated above the active lever during timeout. Experiments were initiated after 17 days of self-administration, when response rates had stabilized ( $<15 \%$ variability over 3 days). Rats ( $n=13$ per group) were then injected with vehicle or $\mathrm{L} 822429(15 \mathrm{mg} / \mathrm{kg}) 1 \mathrm{~h}$ before the next selfadministration session. Each rat received both treatments in a counterbalanced, within-subject design. Self-administration was re-established without drug pretreatment for two sessions between treatment days. Data were analyzed using a dependent samples $t$-test.

Reinstatement experiments were carried out as described (Hansson et al, 2006; Cippitelli et al, 2010; Schank et al, 2011). After 20 days of self-administration, responding was extinguished over 15 daily sessions. Thirty minute extinction sessions were run under the same conditions as selfadministration, but no alcohol was delivered following active lever press. At the conclusion of the extinction phase, all rats $(n=16)$ exhibited $<20$ active lever responses during the $30 \mathrm{~min}$ extinction session. In the reinstatement phase, rats were injected with vehicle or L822429 (15 mg/kg) $30 \mathrm{~min}$ before administration of yohimbine $(2.5 \mathrm{mg} / \mathrm{kg})$. Reinstatement responding was measured under extinction conditions $30 \mathrm{~min}$ after yohimbine injection. Each rat received both L822429 treatment conditions in a counterbalanced order with 2 days of extinction between tests. Because this experiment produced large within-group variability (likely due to anxiety-induced behavioral suppression in a subset of rats), and because it has been reported that a dose of $1.25 \mathrm{mg} / \mathrm{kg}$ yohimbine is also effective at reinstating alcohol seeking (Le et al, 2005), rats were given 4 days of extinction followed by reinstatement testing with this lower dose of yohimbine. In this phase, rats were injected with vehicle or L822429 (15 mg/kg) $30 \mathrm{~min}$ before yohimbine injection $(1.25 \mathrm{mg} / \mathrm{kg})$, as above. Each rat received both pretreatments in a counterbalanced order with 2 days of extinction between tests. The data were analyzed using repeated-measures one-way ANOVA with the within-subjects factor of session. Post hoc group comparisons were performed using Newman-Keuls tests.

\section{Quantitative Real-Time PCR}

Rats ( $n=8-10$ per group) were decapitated, and $2 \mathrm{~mm}$ sections obtained using a Kopf tissue slicer, at the following coordinates relative bregma (4): nucleus accumbens (NAC); caudate putamen (CPU): +0.2 to +2.2 ; amygdala (AMG); and hippocampus (Hipp): -1.8 to -3.8 . Anatomical landmarks were used to obtain punches (AMG: $2 \mathrm{~mm}$ ) or free hand dissected tissue (Hipp, CPU, NAC). Samples were snap frozen in chilled isopentane, and stored at $-80^{\circ} \mathrm{C}$ until analyzed.

a

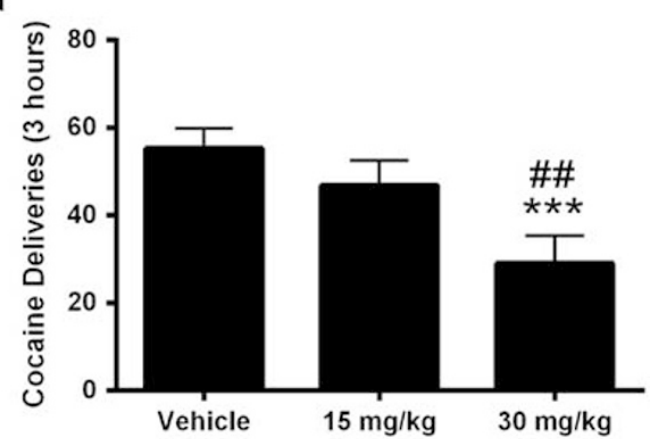

b

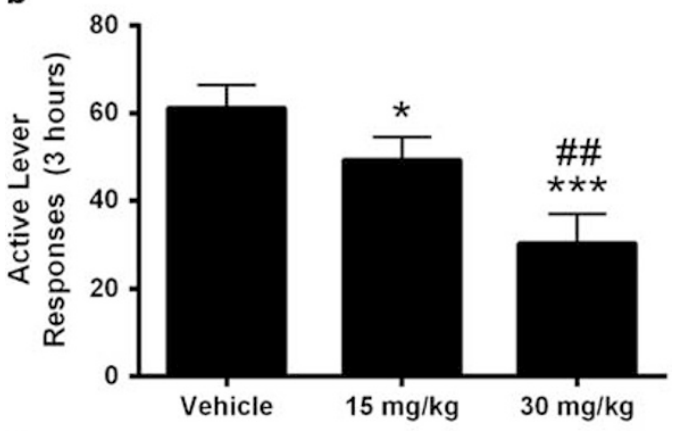

C

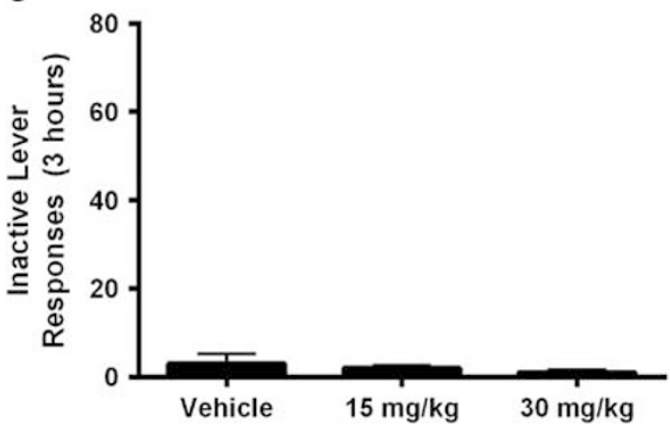

Figure I Effects of L822429 on maintenance cocaine self-administration. Vehicle or L822429 (I 5 or $30 \mathrm{mg} / \mathrm{kg}$, intraperitoneally was injected $60 \mathrm{~min}$ before a cocaine self-administration session (FRI reinforcement schedule, $0.5 \mathrm{mg} / \mathrm{kg}$ per infusion). Shown are the mean \pm SEM number of cocaine deliveries (a), active lever presses (b), and inactive lever presses (c) obtained during the 3 -h session. $* * * P<0.00$ I, $* p<0.05$ compared with vehicle treatment. ${ }^{\# \#} P<0.01$ compared to $15 \mathrm{mg} / \mathrm{kg} L 822429$ treatment. 
Total RNA was extracted using RiboPure kit (Ambion, Grand Island, NY) according to the manufacturer's instructions. RNA concentrations were determined using a NanoDrop 2000 spectrophotometer (Thermo Fisher Scientific, Wilmington, DE). Purified RNA ( $0.4 \mu \mathrm{g}$ for AMG, $1 \mu \mathrm{g}$ for all other regions) was reverse-transcribed using a firststrand cDNA synthesis kit (Invitrogen, Grand Island, NY) according to the manufacturer's instructions. Reactions were in triplicate, using a 1/10 dilution of each cDNA with specific TaqMan probe/primers and TaqMan universal master mix (Applied Biosystems, Foster City, CA), and run on an Applied Biosystems 7900HT PCR machine.

FAM-labeled probes and forward and reverse primers for TacR1 (Rn00562004_m1*; transcript for NK1R) and Gapdh (Rn99999916_s1; housekeeping gene) were selected from Assay on Demand (Applied Biosystems). Cycling parameters were $2 \mathrm{~min}$ at $50^{\circ} \mathrm{C}$ for reverse transcription, $10 \mathrm{~min}$ at $95^{\circ} \mathrm{C}$ for heat inactivation of the reverse transcriptase and activation of the DNA polymerase, and 40 cycles of $15 \mathrm{~s}$ at $95^{\circ} \mathrm{C}$ and $1 \mathrm{~min}$ at $60^{\circ} \mathrm{C}$. Data were analyzed using SDS 2.4. Reactions were normalized to the Gapdh endogenous control and compared between groups using the $2^{\Delta \Delta \mathrm{Ct}}$ method (Livak and Schmittgen, 2001).

\section{Drugs}

L822429 was synthesized by Drs Cheng and Rice (Chemical Biology Research Branch, NIDA), dissolved in $45 \%$ (w/v) 2-hydroxypropyl $\beta$-cyclodextrin (Sigma, St Louis, MO), and $\mathrm{pH}$ was neutralized using $1 \mathrm{~N} \mathrm{NaOH}$. Systemic injections were in $2 \mathrm{ml} / \mathrm{kg}$, intraperitoneally. Yohimbine
(Sigma-Aldrich, St Louis, MO) was dissolved in sterile water and injected intraperitoneally in a volume of $1 \mathrm{ml} / \mathrm{kg}$.

\section{RESULTS}

\section{Effects of L822429 on Cocaine Self-Administration}

Repeated-measures one-way ANOVA revealed a main effect of L822429 treatment $(\mathrm{F}(2,10)=22.3, p<0.0001$; Figure 1a) on the number of cocaine infusions earned by Long-Evans rats in self-administration sessions. Post hoc tests indicated a significant suppression of responding following $30 \mathrm{mg} / \mathrm{kg}$ L822429 treatment compared with both vehicle $(p<0.001)$ and $15 \mathrm{mg} / \mathrm{kg} \mathrm{L} 822429$ treatment $(p<0.01)$. The difference between vehicle treatment and $15 \mathrm{mg} / \mathrm{kg}$ L822429 treatment reached a trend level of significance $(p=0.06)$, with $15 \mathrm{mg} /$ $\mathrm{kg}$ L822429 inducing a slight decrease in responding. Similar results were obtained when comparing active lever responses during the session. Repeated-measures one-way ANOVA revealed a main effect of $\mathrm{L} 822429$ treatment $(\mathrm{F}(2,10)=18.01$, $p<0.001$; Figure 1b). Post hoc comparisons indicated a significant suppression of responding following $30 \mathrm{mg} / \mathrm{kg}$ L822429 treatment compared with both vehicle $(p<0.001)$ and $15 \mathrm{mg} / \mathrm{kg}$ L822429 $(p<0.01)$. There was also a statistically significant decrease in responding after treatment with $15 \mathrm{mg} / \mathrm{kg}$ L822429 when compared with vehicle $(p=0.046)$. Repeated-measures one-way ANOVA did not reveal a main effect of L822429 treatment on the number of inactive lever responses $(\mathrm{F}(2,10)=0.67, p=0.53$; Figure $2 \mathrm{c})$, but this measure showed considerable variability and trended in the same direction as active lever responses. To correct for a
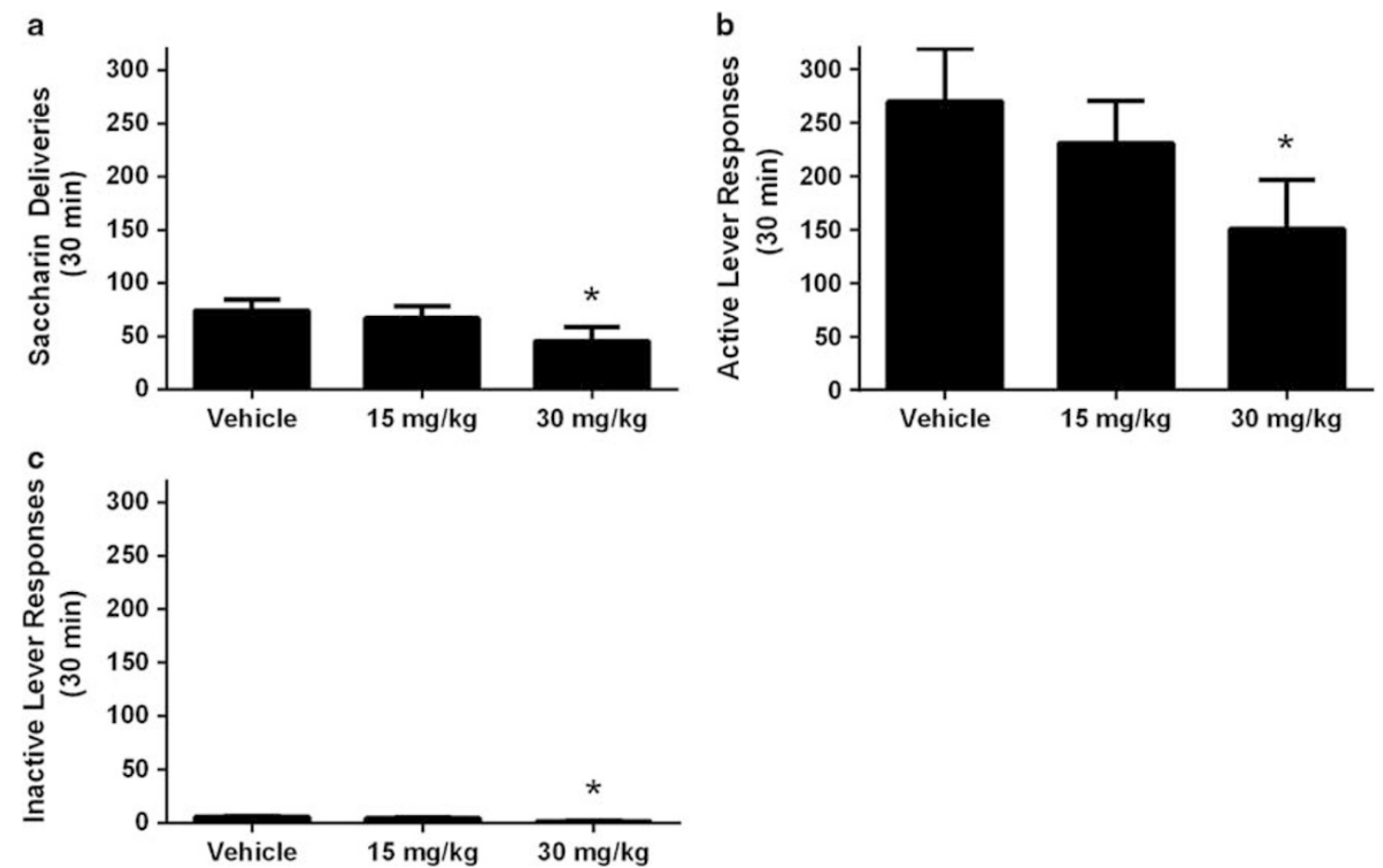

Figure 2 Effects of L822429 on saccharin self-administration. After reaching maintenance criteria, vehicle or L822429 (I5 or $30 \mathrm{mg} / \mathrm{kg}) \mathrm{was}$ injected $60 \mathrm{~min}$ before a saccharin self-administration session (FR3 reinforcement schedule, $0.05 \%(\mathrm{w} / \mathrm{v})$ saccharin concentration). Shown are the mean \pm SEM number of saccharin deliveries (a), active lever presses (b), and inactive lever presses (c) obtained during the 30 min session. $* P<0.05$ compared with vehicle treatment. 
possible confound from behavioral suppression, a difference score (active minus inactive lever presses) was calculated (Le et al, 2005; Karlsson et al, 2012). Mean \pm SEM of difference scores were as follows: vehicle, $58.2 \pm 5.1 ; 15 \mathrm{mg} /$

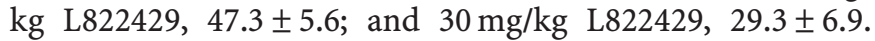
One-way ANOVA analysis of difference scores revealed a main effect of treatment $(\mathrm{F}(2,10)=14.3, p=0.001)$. Post hoc Newman-Keuls tests revealed that responding was suppressed by $30 \mathrm{mg} / \mathrm{kg}$ L822429 ( $p=0.001$ compared with vehicle group), but not $15 \mathrm{mg} / \mathrm{kg}$ L822429 ( $p=0.07$ compared with vehicle group). Combined, these results suggest that L822429 at a dose of $30 \mathrm{mg} / \mathrm{kg}$, but not $15 \mathrm{mg} / \mathrm{kg}$, significantly suppresses cocaine self-administration.

\section{Effects of L822429 on Saccharin Self-Administration}

The high dose $(30 \mathrm{mg} / \mathrm{kg})$, but not the low dose $(15 \mathrm{mg} / \mathrm{kg})$, of L822429 significantly reduced the number of saccharin rewards earned during self-administration sessions. Repeated-measures one-way ANOVA revealed a main effect of L822429 treatment $(\mathrm{F}(2,12)=7.0, p=0.03$; Figure 2a). Post hoc tests indicated a significant decrease in responding following $30 \mathrm{mg} / \mathrm{kg}$ L822429 treatment compared with both vehicle $(p=0.03)$ and $15 \mathrm{mg} / \mathrm{kg} \operatorname{L822429}(p=0.04)$. There was no difference in responding between vehicle treatment and $15 \mathrm{mg} / \mathrm{kg}$ L822429 treatment $(p=0.48)$. Similar results were obtained when comparing active lever responses. Repeated-measures one-way ANOVA revealed a main effect of L822429 treatment on the number of active lever responses $(\mathrm{F}(2,12)=5.6, p=0.02$; Figure $2 \mathrm{~b})$. Post hoc comparisons indicated a significant suppression of responding following $30 \mathrm{mg} / \mathrm{kg}$ L822429 treatment compared with both vehicle $(p=0.02)$ and $15 \mathrm{mg} / \mathrm{kg} \operatorname{L822429}(p=0.046)$. There was no difference in responding between vehicle and $15 \mathrm{mg} / \mathrm{kg}$ L822429 treatment $(p=0.30)$. Repeated-measures one-way ANOVA revealed a main effect of treatment on the number of inactive lever responses $(\mathrm{F}(2,12)=5.0, p=0.03$; Figure $2 \mathrm{c})$. Post hoc comparisons indicated a significant decrease in responding following $30 \mathrm{mg} / \mathrm{kg}$ L822429 treatment when compared with vehicle treatment $(p=0.02)$ but not $15 \mathrm{mg} /$ $\mathrm{kg}$ L822429 treatment $(p=0.053)$. There was no difference in responding between vehicle and $15 \mathrm{mg} / \mathrm{kg}$ L822429 treatment $(p=0.37)$. Combined, these results indicate that the decrease in responding for cocaine observed following pretreatment with $30 \mathrm{mg} / \mathrm{kg} \mathrm{L822429}$ is likely due to nonspecific behavioral suppression. To further confirm that the $15 \mathrm{mg} / \mathrm{kg}$ dose of L822429 lacked sedative properties, we also tested the effect of this compound on general locomotor activity and observed no effect (mean distance traveled \pm SEM; vehicle: $1989 \mathrm{~cm} \pm 137.6$; L822429: $2171 \pm 255.8 ; t(10)=0.62, p=0.54)$.

\section{A Dose of L822429 that does not Affect General Operant Responding Suppresses Yohimbine-Induced Reinstatement of Cocaine Seeking}

Because our experiments revealed a general suppression of operant behavior by the high dose $(30 \mathrm{mg} / \mathrm{kg})$ of $\mathrm{L} 822429$ (see above), we used only the low dose $(15 \mathrm{mg} / \mathrm{kg}$ ) for the remainder of the study. After reaching criteria for stable cocaine self-administration and extinction, responding for cocaine was reinstated using the pharmacological stressor, yohimbine. L822429 (15 mg/kg) robustly suppressed yohimbine-induced reinstatement following extinction. Repeated-measures ANOVA revealed a main effect of treatment $(F(2,14)=23.9, p<0.0001$; Figure 3a) on active lever responding. Post hoc tests showed a significant increase in responding following yohimbine with vehicle pretreatment when compared with extinction responding $(p<0.001)$. Although there was also a significant increase in responding following yohimbine with L822429 pretreatment when compared with extinction $(p=0.045)$, the effects of yohimbine were significantly attenuated by L822429 (vehicle/yohimbine vs L822429/yohimbine post hoc test; $p<0.001)$. One-way ANOVA also revealed a main effect of treatment $(\mathrm{F}(2,14)=15.2, p<0.001$; Figure $3 \mathrm{~b})$ on inactive lever responding during reinstatement. Newman-Keuls post hoc tests showed a significant increase in responding following injection of $2.5 \mathrm{mg} / \mathrm{kg}$ yohimbine with vehicle pretreatment when compared with extinction responding $(p<0.001)$. Inactive lever pressing tends to increase slightly over extinction levels during reinstatement, and is thought to reflect alternate drug seeking or response generalization rather than nonspecific behavioral activation (Shalev et al, 2002; Peters et al, 2008). Similar results were obtained when difference score was used for analysis.
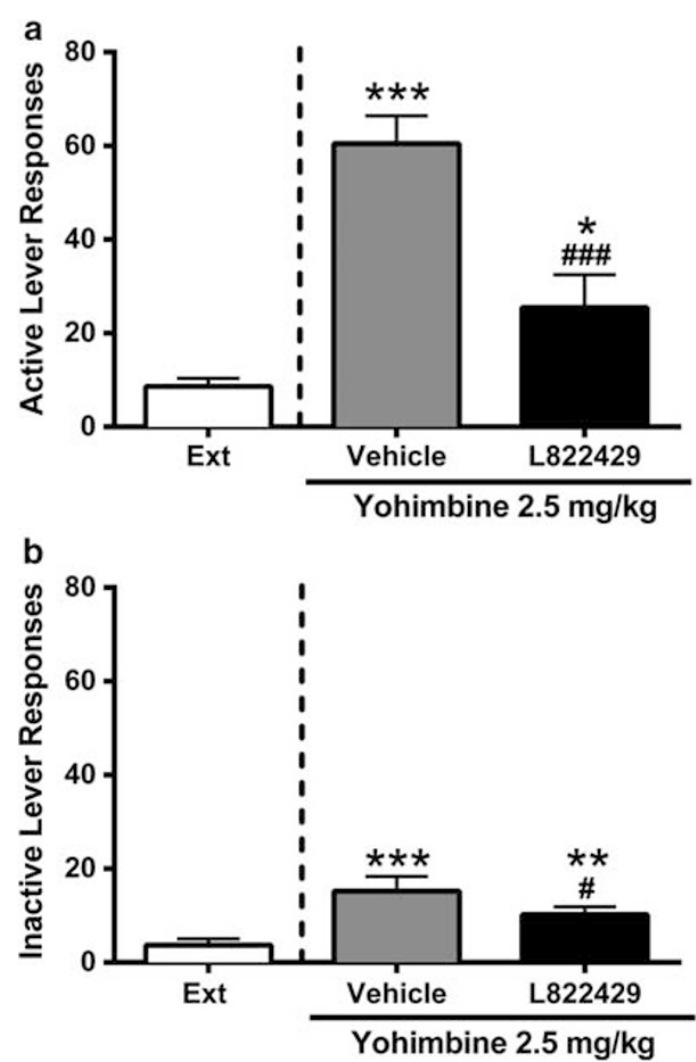

Figure 3 The effects of L822429 on yohimbine-induced reinstatement of cocaine seeking. After reaching maintenance and extinction criteria, rats were pretreated with vehicle or $L 822429(15 \mathrm{mg} / \mathrm{kg}) 30 \mathrm{~min}$ before reinstatement with yohimbine $(2.5 \mathrm{mg} / \mathrm{kg})$. Reinstatement sessions began $30 \mathrm{~min}$ after yohimbine injection. Shown are the mean \pm SEM number of active lever responses (a) and inactive lever reponses (b) during the 3-h session compared with extinction (Ext). **** $<<0.00$ I, *** $p<0.0$ I, * $p<0.05$ compared with extinction responding; ${ }^{*} \# \#<0.001,{ }_{p} p<0.05$ compared with yohimbine with vehicle pretreatment. 


\section{L822429 does not Affect Alcohol Self-Administration}

Paired $t$-test indicated that $\mathrm{L} 822429(15 \mathrm{mg} / \mathrm{kg})$ treatment had no effect on the number of alcohol deliveries obtained $(t(12)=0.58, p=0.57$; Figure $4 \mathrm{a})$, active lever responses $(t(12)=0.21, p=0.84$; Figure $4 \mathrm{~b})$, or inactive lever responses $(t(12)=0.32, p=76$; Figure $4 \mathrm{c})$. These results indicate that, at a dose that lacks general suppression of operant behavior, L822429 does not affect alcohol selfadministration. Similar results were obtained when difference score was used for analysis.

\section{A Dose of L822429 that does not Affect General Operant Responding or Alcohol Self-Administration Potently Suppresses Yohimbine-Induced Reinstatement of Alcohol Seeking}

After reaching the criteria for stable alcohol self-administration and extinction, the effects of L822429 on yohimbineinduced alcohol seeking were assessed. Repeated-measures ANOVA revealed a main effect of treatment $(\mathrm{F}(4,60)=3.9$, $p=0.007$; Figure 5a). Post hoc Newman-Keuls tests indicated that there was a significant increase in responding following the injection of $1.25 \mathrm{mg} / \mathrm{kg}$ yohimbine with vehicle pretreatment when compared with extinction responding $(p=0.02)$. There was also an increase in responding following $2.5 \mathrm{mg} / \mathrm{kg}$ yohimbine with vehicle pretreatment, but it did not reach statistical significance $(p=0.17)$. Thus, in this experiment, the $1.25 \mathrm{mg} / \mathrm{kg}$ dose of yohimbine, but not the $2.5 \mathrm{mg} / \mathrm{kg}$ dose, was an effective reinstatement stimulus for alcohol seeking. Post hoc tests indicated that L822429 significantly reduced yohimbine-induced reinstate- ment at the $1.25 \mathrm{mg} / \mathrm{kg}$ dose when compared with vehicle pretreatment $(p=0.03)$. Inactive lever responses were not significantly affected by treatment, although a trend was observed $(\mathrm{F}(4,60)=2.5, p=0.06)$. Combined, these results indicate that $15 \mathrm{mg} / \mathrm{kg}$ L822429 attenuates stress-induced reinstatement of alcohol seeking that is triggered by injection of $1.25 \mathrm{mg} / \mathrm{kg}$ yohimbine. Similar results were obtained when difference score was used for analysis.

\section{Long-Evans Rats Exhibit Lower Levels of NK1R Expression Compared to Wistar Rats}

In these experiments using Long-Evans rats, we observed nonspecific sedative effects at a dose of L822429 (30 mg/kg) that we have previously shown to lack such effects in Wistar rats. To investigate this altered sensitivity to NK1R antagonism in Long-Evans rats relative to the sensitivity observed in Wistar rats in previous experiments, we assessed the level of NK1R expression in a subset of subcortical brain regions associated with self-administration and relapse-like behavior. We observed lower NK1R transcript levels in the NAC $(t(16)=2.51, p=0.02,20 \%$ decrease) and Hipp $(t(16)=2.12, p=0.05,13 \%$ decrease $)$, but no differences in the AMG $(t(16)=0.15, p=0.88)$ or $\mathrm{CPU}(t(16)=0.98, p=0.34)$.

\section{DISCUSSION}

In these experiments, we show that the NK1R antagonist L822429 attenuates yohimbine-induced reinstatement of cocaine seeking at a dose that lacks nonspecific effects on a

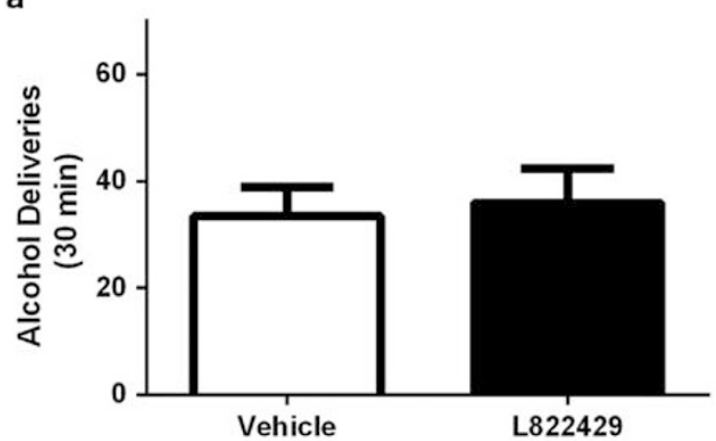

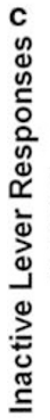

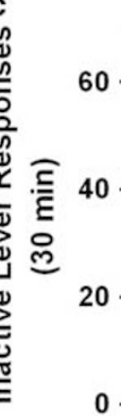

b

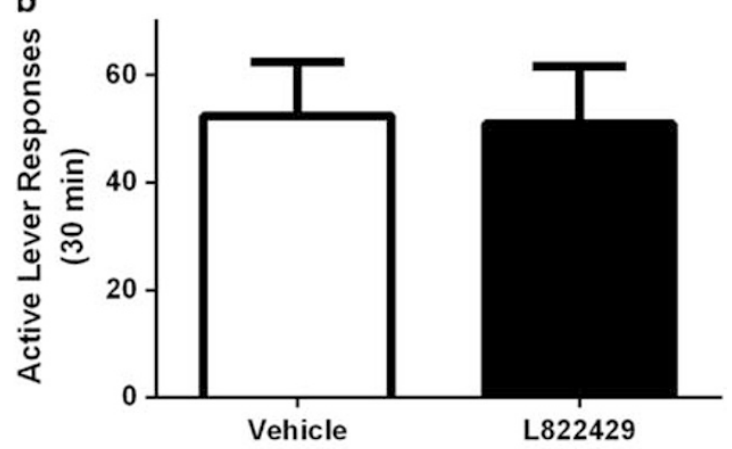

Figure 4 Effects of L822429 on alcohol self-administration. After reaching maintenance criteria, vehicle or L822429 (I $5 \mathrm{mg} / \mathrm{kg}$ ) was injected $60 \mathrm{~min}$ before an alcohol self-administration session (FRI reinforcement schedule, 10\% ( $/ / \mathrm{v})$ alcohol concentration). Shown are the mean \pm SEM number of alcohol deliveries (a), active lever presses (b), and inactive lever presses (c) obtained during the 30 min session. 

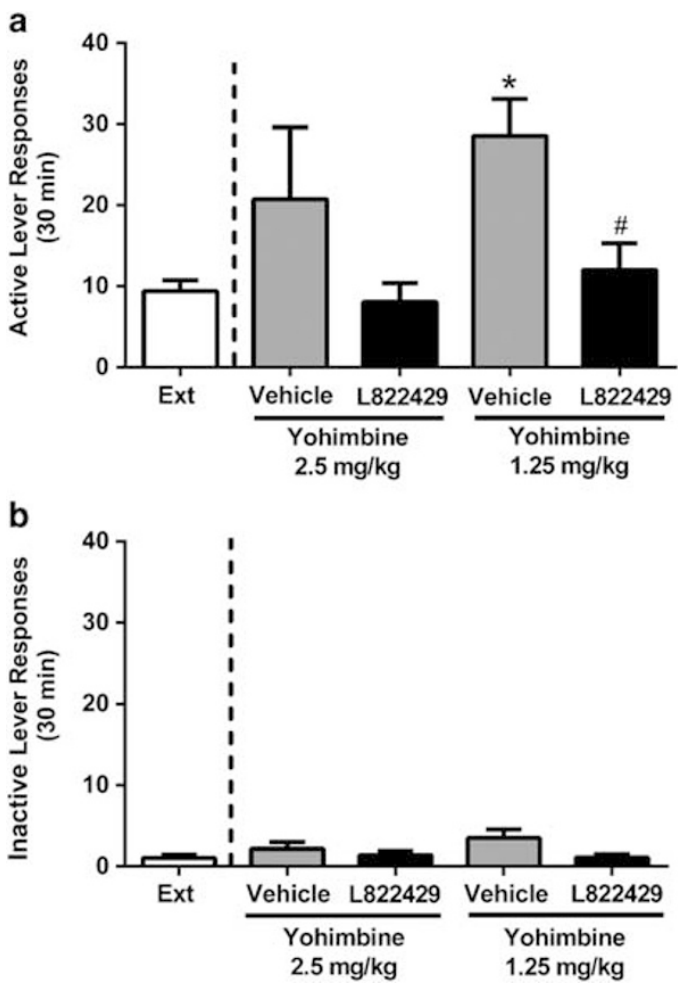

Figure 5 Effects of L822429 on yohimbine-induced reinstatement of alcohol seeking. After reaching maintenance and extinction criteria, rats were pretreated with vehicle or $L 822429(15 \mathrm{mg} / \mathrm{kg}) 30 \mathrm{~min}$ before reinstatement with yohimbine $(1.25$ or $2.5 \mathrm{mg} / \mathrm{kg})$. Reinstatement sessions were begun $30 \mathrm{~min}$ after yohimbine injection. Shown are the mean \pm SEM number of active lever responses (a) and inactive lever responses (b) during the $30 \mathrm{~min}$ session. $* P<0.05$ compared with extinction responding; ${ }^{\#} p<0.05$ compared with vehicle pretreatment for that dose of yohimbine.

operant behavior. We also show that L822429 attenuates yohimbine-induced reinstatement of alcohol seeking at a dose that does not alter alcohol self-administration. The latter finding largely replicates what we have observed using footshock-induced reinstatement of alcohol seeking (Schank et al, 2011). Surprisingly, a dose of L822429 (30 mg/ $\mathrm{kg}$ ) that lacks nonspecific behavioral suppression in Wistar rats suppresses saccharin self-administration in the Long-Evans strain. Analysis of the NK1R system by measurement of NK1R expression revealed that NK1R transcript levels were decreased in Long-Evans rats relative to Wistar controls.

Our finding that L822429 can attenuate yohimbineinduced reinstatement of cocaine seeking is consistent with reports that intracranial infusion of a SP analog can trigger reinstatement of cocaine seeking (Placenza et al, 2005), and that stressors induce the release of SP. An intriguing question for future studies is whether NK1R antagonism might influence cocaine self-administration during longaccess sessions, which promote escalated cocaine selfadministration rates, potentially through recruitment of stress-related systems (Specio et al, 2008; Wee et al, 2008, 2009). In support of this idea, NK1R antagonists suppress alcohol consumption in a high alcohol preferring line of mice (C57/BL6J) and attenuate escalated alcohol selfadministration in alcohol preferring $(\mathrm{P})$ rats, but do not affect alcohol self-administration in non-dependent, nonpreferring rats (Thorsell et al, 2010; Schank et al, 2011, 2013).

Our study is among the first to assess the effect of acute NK1R antagonism on operant cocaine self-administration in rats. In our experiments, the dose of L822429 (30 mg/kg) that suppressed cocaine self-administration also suppressed saccharin self-administration. Some mild effects on cocaine self-administration were observed with $15 \mathrm{mg} / \mathrm{kg}$ L822429. These effects were modest (approximately 20\% decrease in active lever responses; effect on infusions only trend level), especially when considered in comparison with the effect of the antagonist on yohimbine-induced reinstatement of cocaine seeking (nearly $60 \%$ decrease in active lever responding). Given the small magnitude of this effect on cocaine self-administration, both in absolute terms as well as in statistical significance, we reanalyzed these data using a difference score, which can correct for a mild suppression of operant behavior that may have driven this slight suppression in responding. This analysis showed no major effect of L822429 at $15 \mathrm{mg} / \mathrm{kg}$. This agrees with a previous study that found no effect of NK1R antagonism on baseline cocaine self-administration (Placenza et al, 2006). It is important to note, however, that the cocaine self-administration experiment used an FR1 schedule of reinforcement, and it is possible that NK1R antagonism may have a greater impact on responding on an FR schedule with a greater response requirement. This concern is somewhat alleviated by the fact that the saccharin self-administration control experiment used an FR3 schedule of reinforcement, and did not show any suppressant activity at the $15 \mathrm{mg} / \mathrm{kg}$ dose.

We have previously reported that L822429, at doses up to $30 \mathrm{mg} / \mathrm{kg}$, does not affect self-administration of sucrose or alcohol, locomotor activity, or cue-induced reinstatement of alcohol seeking in Wistar rats (Schank et al, 2011). However, in the experiments presented here we observed nonspecific sedative effects at $30 \mathrm{mg} / \mathrm{kg}$. Therefore, we assessed the baseline state of the NK1R system by measuring transcript levels in subcortical brain regions and found NK1R levels to be decreased in Long-Evans rats relative to the Wistar strain in the NAC and Hipp, which may contribute to the differential sensitivity to NK1R antagonism. This may seem to contradict our previous findings of increased NK1R expression and increased sensitivity to NK1R antagonism in alcohol-preferring $\mathrm{P}$ rats relative to Wistar controls (Schank et al, 2013). However, downregulation of the receptor transcript in the present case may indicate SP/NK1R system hyperfunction due to increased presynaptic SP drive, which could potentially lead to decreased postsynaptic receptor levels. In the case of $\mathrm{P}$ rats, NK1R upregulation may be the primary factor driving increased SP/NK1R system activity.

Combined, our findings indicate that NK1R antagonism can attenuate stress-induced reinstatement of drug seeking for multiple classes of drugs including psychostimulants and alcohol. Although not tested in this study, we would predict that NK1R antagonists would also suppress stressinduced reinstatement of opiate seeking based on our results and previous data showing that the NK1R can regulate a wide range of opiate-seeking behaviors (Murtra et al, 2000; Ripley et al, 2002; Gadd et al, 2003; Robinson et al, 2012). 
The profile of NK1R antagonist effects is reminiscent of that observed with $\mathrm{CRH}$ receptor type 1 (CRH1) antagonists. In preclinical models, $\mathrm{CRH} 1$ antagonists suppress stressinduced reinstatement, decrease withdrawal-induced anxiety, and blunt escalated drug self-administration in genetically selected or drug-dependent animals. However, they do not affect self-administration in non-dependent, non-genetically selected animals, and do not affect cue-induced reinstatement (Erb et al, 1998; Shaham et al, 1998; Le et al, 2000; Liu and Weiss, 2002; Gehlert et al, 2007; Heilig and Koob, 2007; Specio et al, 2008, Greenwell et al, 2009).

These findings have significant implications for the development of addiction pharmacotherapies. Consistent with the present results, outcomes from one clinical trial suggest that NK1R antagonists can suppress both spontaneous and challenge-induced alcohol craving in detoxified alcoholics (George et al, 2008). Interestingly, other groups have shown that genetic variants of the TacR 1 gene are associated with increased risk for alcohol dependence and increased responsiveness to alcohol-related cues (Seneviratne et al, 2009; Blaine et al, 2013). However, no clinical trials have explored the effect of NK1R antagonists on alcohol consumption in outpatient alcoholics, and such studies seem warranted. Our results also suggest that NK1R antagonists could have utility for the treatment of cocaine use disorders, which has not been explored in a clinical setting. The effect of NK1R antagonism on relapse-like behavior involving multiple classes of drugs is especially pertinent in light of the fact that many drug users exhibit polysubstance abuse.

\section{FUNDING AND DISCLOSURE}

The authors declare that, except for income received from primary employers, no financial support or compensation has been received from any individual or corporate entity over the past three years for research or professional service and there are no personal financial holdings that could be perceived as constituting a potential conflict of interest.

\section{ACKNOWLEDGEMENTS}

This work was funded by the National Institute on Alcohol Abuse and Alcoholism Intramural Research Program, the National Institute on Drug Abuse Intramural Research Program, and the National Institute of Drug Abuse (RO1DA027535 to DW), and Grant K99AA021805 (JRS). The content is solely the responsibility of the authors and does not necessarily represent the official views of the National Institutes of Health.

\section{REFERENCES}

Barbier E, Vendruscolo LF, Schlosburg JE, Edwards S, Juergens N, Park PE et al (2012). The NK1 receptor antagonist L822429 reduces heroin reinforcement. Neuropsychopharmacology 38: 976-984.

Blaine S, Claus E, Harlaar N, Hutchison K (2013). TACR1 genotypes predict fMRI response to alcohol cues and level of alcohol dependence. Alcohol Clin Exp Res 37(Suppl 1): E125-E130.

Cippitelli A, Damadzic R, Hansson AC, Singley E, Sommer WH, Eskay $\mathrm{R}$ et al (2010). Neuropeptide Y (NPY) suppresses yohimbine-induced reinstatement of alcohol seeking. Psychopharmacology (Berl) 208: 417-426.

Commons KG (2010). Neuronal pathways linking substance P to drug addiction and stress. Brain Res 1314: 175-182.

Ebner K, Muigg P, Singewald G, Singewald N (2008a). Substance P in stress and anxiety: NK-1 receptor antagonism interacts with key brain areas of the stress circuitry. Ann N Y Acad Sci 1144: 61-73.

Ebner K, Rupniak NM, Saria A, Singewald N (2004). Substance P in the medial amygdala: emotional stress-sensitive release and modulation of anxiety-related behavior in rats. Proc Natl Acad Sci USA 101: 4280-4285.

Ebner K, Singewald GM, Whittle N, Ferraguti F, Singewald N (2008b). Neurokinin 1 receptor antagonism promotes active stress coping via enhanced septal 5-HT transmission. Neuropsychopharmacology 33: 1929-1941.

Ebner K, Singewald N (2006). The role of substance P in stress and anxiety responses. Amino Acids 31: 251-272.

Epstein DH, Preston KL, Stewart J, Shaham Y (2006). Toward a model of drug relapse: an assessment of the validity of the reinstatement procedure. Psychopharmacology (Berl) 189: 1-16.

Erb S, Shaham Y, Stewart J (1998). The role of corticotropinreleasing factor and corticosterone in stress- and cocaine-induced relapse to cocaine seeking in rats. J Neurosci 18: 5529-5536.

Feltenstein MW, See RE (2006). Potentiation of cue-induced reinstatement of cocaine-seeking in rats by the anxiogenic drug yohimbine. Behav Brain Res 174: 1-8.

Fletcher PJ, Rizos Z, Sinyard J, Tampakeras M, Higgins GA (2008). The 5-HT2C receptor agonist Ro60-0175 reduces cocaine selfadministration and reinstatement induced by the stressor yohimbine, and contextual cues. Neuropsychopharmacology 33: 1402-1412.

Gadd CA, Murtra P, De Felipe C, Hunt SP (2003). Neurokinin-1 receptor-expressing neurons in the amygdala modulate morphine reward and anxiety behaviors in the mouse. J Neurosci 23: 8271-8280.

Gehlert DR, Cippitelli A, Thorsell A, Le AD, Hipskind PA, Hamdouchi C et al (2007). 3-(4-Chloro-2-morpholin-4-ylthiazol-5-yl)-8-(1-ethylpropyl)-2,6-dimethyl-imidazo[1,2-b]pyridazine: a novel brain-penetrant, orally available corticotropinreleasing factor receptor 1 antagonist with efficacy in animal models of alcoholism. J Neurosci 27: 2718-2726.

George DT, Gilman J, Hersh J, Thorsell A, Herion D, Geyer C et al (2008). Neurokinin 1 receptor antagonism as a possible therapy for alcoholism. Science 319: 1536-1539.

Greenwell TN, Funk CK, Cottone P, Richardson HN, Chen SA, Rice $\mathrm{KC}$ et al (2009). Corticotropin-releasing factor-1 receptor antagonists decrease heroin self-administration in long- but not short-access rats. Addict Biol 14: 130-143.

Hansson AC, Cippitelli A, Sommer WH, Fedeli A, Bjork K, Soverchia L et al (2006). Variation at the rat Crhr1 locus and sensitivity to relapse into alcohol seeking induced by environmental stress. Proc Natl Acad Sci USA 103: 15236-15241.

Heilig M, Koob GF (2007). A key role for corticotropin-releasing factor in alcohol dependence. Trends Neurosci 30: 399-406.

Karlsson C, Zook M, Ciccocioppo R, Gehlert DR, Thorsell A, Heilig $\mathrm{M}$ et al (2012). Melanin-concentrating hormone receptor 1 (MCH1-R) antagonism: reduced appetite for calories and suppression of addictive-like behaviors. Pharmacol Biochem Behav 102: 400-406.

Kraft M, Ahluwahlia S, Angulo JA (2001a). Neurokinin-1 receptor antagonists block acute cocaine-induced horizontal locomotion. Ann N Y Acad Sci 937: 132-139.

Kraft M, Noailles P, Angulo JA (2001b). Substance P modulates cocaine-evoked dopamine overflow in the striatum of the rat brain. Ann N Y Acad Sci 937: 121-131.

Le A, Shaham Y (2002). Neurobiology of relapse to alcohol in rats. Pharmacol Ther 94: 137-156. 
Le AD, Harding S, Juzytsch W, Funk D, Shaham Y (2005). Role of alpha-2 adrenoceptors in stress-induced reinstatement of alcohol seeking and alcohol self-administration in rats. Psychopharmacology (Berl) 179: 366-373.

Le AD, Harding S, Juzytsch W, Watchus J, Shalev U, Shaham Y (2000). The role of corticotrophin-releasing factor in stressinduced relapse to alcohol-seeking behavior in rats. Psychopharmacology (Berl) 150: 317-324.

Lee B, Tiefenbacher S, Platt DM, Spealman RD (2004). Pharmacological blockade of alpha2-adrenoceptors induces reinstatement of cocaine-seeking behavior in squirrel monkeys. Neuropsychopharmacology 29: 686-693.

Liu X, Weiss F (2002). Additive Effect of Stress and Drug Cues on Reinstatement of Ethanol Seeking: Exacerbation by History of Dependence and Role of Concurrent Activation of Corticotropin-Releasing Factor and Opioid Mechanisms. Soc Neuroscience vol. 22, pp 7856-7861.

Livak KJ, Schmittgen TD (2001). Analysis of relative gene expression data using real-time quantitative PCR and the 2(-Delta Delta C(T)) Method. Methods 25: 402-408.

Loonam TM, Noailles PA, Yu J, Zhu JP, Angulo JA (2003). Substance $\mathrm{P}$ and cholecystokinin regulate neurochemical responses to cocaine and methamphetamine in the striatum. Life Sci 73: 727-739.

Murtra P, Sheasby AM, Hunt SP, De Felipe C (2000). Rewarding effects of opiates are absent in mice lacking the receptor for substance P. Nature 405: 180-183.

Noailles PA, Angulo JA (2002). Neurokinin receptors modulate the neurochemical actions of cocaine. Ann N Y Acad Sci 965: 267-273.

Peters J, LaLumiere RT, Kalivas PW (2008). Infralimbic prefrontal cortex is responsible for inhibiting cocaine seeking in extinguished rats. J Neurosci 28: 6046-6053.

Placenza FM, Fletcher PJ, Vaccarino FJ, Erb S (2006). Effects of central neurokinin-1 receptor antagonism on cocaine- and opiate-induced locomotor activity and self-administration behaviour in rats. Pharmacol Biochem Behav 84: 94-101.

Placenza FM, Vaccarino FJ, Fletcher PJ, Erb S (2005). Activation of central neurokinin-1 receptors induces reinstatement of cocaineseeking behavior. Neurosci Lett 390: 42-47.

Ripley TL, Gadd CA, De Felipe C, Hunt SP, Stephens DN (2002). Lack of self-administration and behavioural sensitisation to morphine, but not cocaine, in mice lacking NK1 receptors. Neuropharmacology 43: 1258-1268.

Robinson JE, Fish EW, Krouse MC, Thorsell A, Heilig M, Malanga CJ (2012). Potentiation of brain stimulation reward by morphine: effects of neurokinin-1 receptor antagonism. Psychopharmacology (Berl) 220: 215-224.

Schank JR, Pickens CL, Rowe KE, Cheng K, Thorsell A, Rice KC et al (2011). Stress-induced reinstatement of alcohol-seeking in rats is selectively suppressed by the neurokinin 1 (NK1) antagonist L822429. Psychopharmacology (Berl) 218: 111-119.
Schank JR, Ryabinin AE, Giardino WJ, Ciccocioppo R, Heilig M (2012). Stress-related neuropeptides and addictive behaviors: beyond the usual suspects. Neuron 76: 192-208.

Schank JR, Tapocik JD, Barbier E, Damadzic R, Eskay RL, Sun H et al (2013). Tacrl gene variation and neurokinin 1 receptor expression is associated with antagonist efficacy in genetically selected alcohol-preferring rats. Biol Psychiatry 73: 774-781.

Schroeder JP, Alisha Epps S, Grice TW, Weinshenker D (2013). The selective dopamine beta-hydroxylase inhibitor nepicastat attenuates multiple aspects of cocaine-seeking behavior. Neuropsychopharmacology 38: 1032-1038.

Seneviratne C, Ait-Daoud N, Ma JZ, Chen G, Johnson BA, Li MD (2009). Susceptibility locus in neurokinin-1 receptor gene associated with alcohol dependence. Neuropsychopharmacology 34: 2442-2449.

Shaham Y, Erb S, Leung S, Buczek Y, Stewart J (1998). CP-154,526, a selective, non-peptide antagonist of the corticotropin-releasing factor1 receptor attenuates stress-induced relapse to drug seeking in cocaine- and heroin-trained rats. Psychopharmacology (Berl) 137: 184-190.

Shaham Y, Shalev U, Lu L, De Wit H, Stewart J (2003). The reinstatement model of drug relapse: history, methodology and major findings. Psychopharmacology (Berl) 168: 3-20.

Shalev U, Grimm JW, Shaham Y (2002). Neurobiology of relapse to heroin and cocaine seeking: a review. Pharmacol Rev 54: 1-42.

Shepard JD, Bossert JM, Liu SY, Shaham Y (2004a). The anxiogenic drug yohimbine reinstates methamphetamine seeking in a rat model of drug relapse. Biological psychiatry 55: 1082-1089.

Shepard JD, Bossert JM, Liu SY, Shaham Y (2004b). The anxiogenic drug yohimbine reinstates methamphetamine seeking in a rat model of drug relapse. Biol Psychiatry 55: 1082-1089.

Singewald N, Chicchi GG, Thurner CC, Tsao KL, Spetea M, Schmidhammer $\mathrm{H}$ et al (2008). Modulation of basal and stressinduced amygdaloid substance $\mathrm{P}$ release by the potent and selective NK1 receptor antagonist L-822429. J Neurochem 106: 2476-2488.

Specio SE, Wee S, O'Dell LE, Boutrel B, Zorrilla EP, Koob GF (2008). $\mathrm{CRF}(1)$ receptor antagonists attenuate escalated cocaine self-administration in rats. Psychopharmacology (Berl) 196: 473-482.

Thorsell A, Schank JR, Singley E, Hunt SP, Heilig M (2010). Neurokinin-1 receptors (NK1R:s), alcohol consumption, and alcohol reward in mice. Psychopharmacology (Berl) 209: 103-111.

Wee S, Mandyam CD, Lekic DM, Koob GF (2008). Alpha 1noradrenergic system role in increased motivation for cocaine intake in rats with prolonged access. Eur Neuropsychopharmacol 18: 303-311.

Wee S, Orio L, Ghirmai S, Cashman JR, Koob GF (2009). Inhibition of kappa opioid receptors attenuated increased cocaine intake in rats with extended access to cocaine. Psychopharmacology (Berl) 205: 565-575. 